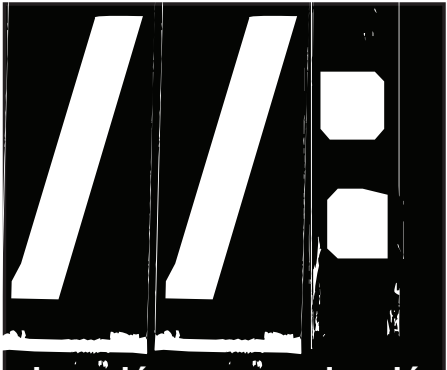

educación y cömunicación 6: 129-138 Mayo 2013

\section{DESVELANDO IMÁGENES DE UN SERTÃO “SECO Y CON HAMBRE” Y RESIGNIFICANDO SABERES. Una propuesta de educación contextualizada para la convivencia con el semiárido brasileño}

\author{
Revealing Images From “Un Sertão "seco y con hambre”. A Proposal \\ for Contextualised Education for the Coexistence with the Semi- \\ arid Region of Brazilian
}

Luzineide Dourado Carvalho

E.mail: ldcarvalho@uneb.br

Doctora en Geografía; Docente UNEB/DCH III donde coordina el NEPEC-SAB (Núcleo de Estudos, Pesquisa e Extensão em Educação Contextualizada para a Convivência com o Semiárido Brasileiro) Universidad Estadual de Bahia. (Brasil)

\section{Resumen:}

El artículo discute sobre las representaciones sociales de la territorialidad del Sertão semiárido presentes en las imágenes de los materiales didácticos, evaluando cuánto muestran una visión peyorativa, negativa o llena de prejuicios en relación con la naturaleza, el territorio y de las gentes de este espacio geográfico brasileño. En este sentido, se presente la vertiente educativa y cultural impulsada por la "convivencia con el semiárido brasileño" y como se viene construyendo un modelo de educación contextualizada. Se analizan las prácticas y metodologías de esa propuesta educativa y como ellas generan el sentido de pertenencia de los moradores sobre sus condiciones de territorialidad, al ser concebidas en un contexto físico y simbólico-cultural en un entorno semiárido. Se presentan algunas formas de actuar con la educación contextualizada en espacios formales y no formales, además de la importancia que tiene la construcción de los discursos desvelándose imágenes negativas sobre los saberes del Sertão.

Palabras clave: Sertão semiárido, territorialidad, libros de texto, educación contextualizada

\section{Abstract:}

This Article proposes to discuss the social representations from the semi-arid Sertão region of Brazil through the images present in didactic materials, and sets out to evaluate how much these show pejorative aspects of this region, and how these transmit prejudices as regards both the physical nature of this region and its peoples. In this respect, we present the educative and cultural aspects that have been boosted by the initiative "coexistence with the semi-arid region" and how this has constructed a contextualized educative model. We shall analyse the practical methodologies of this educative proposal and how this promotes a sense of belonging as regards its territorial conditions, as this is seen as both a physical and culturally symbolic in the semi-arid region. We shall propose certain ways of good practice as regards contextualised education both with in formal and informal contexts, as well as the importance of the discourses that produce negative images about the reality of the Sertão.

Key words: Semi-arid Sertão, territory, text books, contextualized education.

Recibido: 13-02-2013 / Revisado: 11-03-2013 / Aceptado: 05-04-2013 / Publicado: 01-05-2013

https://dx.doi.org/10.25267/Hachetetepe.2013.v1.i6.11 


\section{II: Educación ambiental y fotografía}

\section{La territorialidad del Sertão semiárido}

$\mathrm{E}^{\mathrm{i}}$ Sertão trae consigo las marcas del proceso colonizador de las tierras brasileñas, reflejando el lenguaje del otro, del civilizado. Como enfatiza Almeida (1998: 37), "era una forma de nombrar lo desconocido, expresando el pensamiento del europeo sobre el nuevo continente. El Sertão reforzaba el distanciamiento entre el yo y el otro". El Sertão ganó un paisaje asociado a la Caantinga, al semiárido brasileño (1). Pero, éste no está cerrado a esa vegetación ni a un espacio cartográfico con fronteras. Él es "un concepto complejo, inacabado, en permanente proceso de construcción, cuyas fronteras o ausencias guardan una multiplicidad de sentidos y definiciones" (Mendes: 2009: 69).

De este modo, el semiárido es, por tanto, uno de los tantos 'Sertões' presentes en la territorialidad de este vasto Brasil. Sin embargo, es un territorio concebido como lugar de repulsa, extraño, hostil, cuya presencia de la Caantiga, la vegetación predominante, marca el paisaje, visto como monótono y al mismo tiempo agresivo: "De tramas espinescentes", "folhas urticantes" e "gravetos estalados em lança", relata Euclides da Cunha, en el libro Os Sertões (1991).

Tal ambiente, tomado como hostil, fue incorporado a la nación brasileña en su actualidad, caracterizando la identidad sertaneja por exclusión socio-territorial siendo, de ese modo, naturaleza y hombre marcados por la misma estereotipia: El Sertão de hombres “apáticos y enyesados" (Bassand, 1999: 110) apud (Almeida, 2005), de tipos humanos con un modo de vida tradicionalmente resignado, víctima de la seca, miserable, mesiánico, conforme o inconforme con la penuria. En este sentido, el concepto Caantiga adentra en la literatura como un ambiente hostil, marcado por la pobreza. Tal perspectiva equivocada aún pervive en la actualidad, haciéndose hincapié en los libros de texto y en la forma de cómo se presente esa vegetación. Para Almeida (2007), son concepciones que remiten a la Caantiga como un lugar de exclusión socio territorial donde habitan y superviven precariamente los caantingueiros (habitantes de la Caantiga). Esta afirmación se refuerza en este ejemplo sobre geografía:

\begin{abstract}
«A menos de $90 \mathrm{~km}$ del mar (...) vegetan tan sólo los cactus y los arbustos espinosos y retorcidos. Un paisaje seco y pobre, contratando tristemente con el panorama vivo y alegre del mar y de la vegetación que quedaron atrás (...). Lo que caracteriza a esa vegetación es su homogeneidad, es decir, el mismo aspecto siempre» (Branco, 1994: 6-7).
\end{abstract}

La Caatinga ha sido un ecosistema brasileño "reducido a un espacio de supervivientes" (Santos, 2005: 77). No obstante, "no puede ser entendido como un espacio feo e inhóspito, pero con una belleza y riqueza peculiar, admirada, amada por las personas que viven en esos espacios desde hace siglos". Este autor aún resalta más la identidad sertaneja:

\footnotetext{
«La gente que habitan los diferentes paisajes geohumanos de esa región del Brasil (...) hombre y mujeres del semiárido viven en procesos simbióticos con el bioma Caantiga concentrándose alrededor de ciudades mayores, polos industriales y perímetros irrigados (...) una ecología específica, donde la gente del Sertão se relacionan de forma sistémica» (Santos, 2005: 75-77)
}

Esta lectura no dimensionará la complejidad de los 


\section{/: Desvelando imágenes de un sertão "seco I y con hambre" y resignificando saberes}

espacios geohumanos del semiárido, pero sí, descualificarán toda la etnobiodiversidad de la Caantiga. Tal como apunta Santos (2005: 77): "Un ecosistema brasileño que no puede ser entendido como un local feo y habitado". La rica diversidad histórica, cultural, económica, social, política y ambiental del Sertão semiárido ha sido destacada tan sólo por sus aspectos negativos. La interacción del sertanejo con la Caantiga ha recibido una interpretación apriorística, donde la particularidad de la existencia y de la organización socioeconómica del sertanjeo con su medio físico y simbólico, sus singularidades y potencialidades, además de las revelaciones en las formas de uso y de vivencia de esos hombres y mujeres con sus recursos naturales y culturales no son expresiones valoradas como un patrimonio de identidad. El sertanejo, una vez absorbido por la naturaleza semiárida, hace de éste su escenario para construir su imaginario, sus creencias, sus prácticas materiales e inmateriales en relación con su lugar y con el mundo. Una territorialidad dimensionada con múltiplos significados vividos entre el hombre, la naturaleza y la cultura. Sentidos que podrían ser interpretados en palabras de Bonnemaison (2002: 03) como "una relación secreta y emocional que liga los hombres a su tierra y, a la vez, funda su identidad cultural".

\section{Dizibilidades y visibilidad construida en torno al Sertão semiárido}

La presencia de la seca se engloba en la propia dinámica ambiental de las llamadas tierras secas, que incluyen todas las zonas áridas, semiáridas y sub húmedas del mundo (Brasil, 2004). Los registros de grandes secas están presenten a lo largo de la historia en cuanto a la formación y organización geo-económica del semiárido brasileño. Esta seca ha sido comunicada, presentada y representada por sus connotaciones de hostilidad, como algo atípico. Como denominó Albuquerque Jr. (1999), son dizibilidades y visibilidades sobre esta región, o sea, a partir de lo expuesto en el cine, en los discursos parlamentarios, en la prensa, etc. presentándose imágenes de calamidad, de pobreza y personas itinerantes, institucionalizando los estereotipos de una naturaleza (pobre, fea, adversa, de vegetación muerta) y del sertanejo (o persona de cabeza achatada, ignorante, víctima del poder del sur).

La fuerza de esas narrativas legitiman y se apropian de un discurso político-ideológico sobre la seca impulsado por las elites nordestinas (región a la que pertenece el semiárido), que según Albuquerque Jr. (1999) supieron utilizar política y económicamente todas las circunstancias, conjuras y necesidades de cada momento de la seca para mantenerse y perpetuarse por generaciones en el poder local y regional, conspirando con el poder central y manipulando los recursos destinados a las obras de regadíos en tiempos de sequía.

Según cita Carvalho (2012) la política combate la seca, sin quedar exenta del así desgaste de tantos fallos, falta de continuidad o desperdiciados proyectos, planos o programas estatales, con el propósito de "solucionar el problema de la región del nordeste" que se extiende hasta finales del siglo XX. Mientras que la transición para el siglo XXI trajo nuevas cuestiones y nuevos actores sociales para la producción y organización del semiárido. Nueva agencias y arreglos productivos que provocaron la reflexión, el debate y la crítica estimulante sobre la política de combate a la seca por parte del Estado. 


\section{Las imágenes de un Sertão "seco y de hambre" presente en los materiales didácticos}

En instituciones formativas, como es la escuela, se constata la reproducción de imágenes y discursos de la descalificación representada en el semiárido brasileño; de modo que una vez que aparecen en los materiales didácticos, en especial en libros que utilizan el alumnado y profesorado, se convierten en la exclusiva lectura y orientación metodológica. Hoy el libro didáctico es un gran aliado del profesorado en su práctica pedagógica; en algunos casos, se convierte en el único. En verdad, este libro surge como una herramienta esencial de sistematización de la información, pues trae una carga de conocimientos y experiencias acumuladas a lo largo del tiempo (Sena, 2012). En este sentido, corrobora Pereira (2012: 62) apud Sena (2012: 41):

\begin{abstract}
«Éste, muchas veces, es el único instrumento que el profesor cuenta como apoyo en una clase. Al ser así concebido pasa a tener como principal función estructurar el trabajo pedagógico del profesor mediante la presentación, de acuerdo con las disciplinas, de los contenidos curriculares estereotipados e inamovibles por determinada cultura en detrimento de otras»
\end{abstract}

Según Sena (2012), en la perspectiva general de los libros de texto, las características de este territorio son sólo climáticas y no delinean un espacio históricosocial o describe las características propias de un pueblo. Además de algunos otros aspectos presentados que no enmarcan cuestiones históricas. Con ello, se mantiene demasiado desarrollado el tema de la seca, manteniendo el estigma del Nordeste. En estas narrativas, aparecen algunos temas correlacionados con la seca, tales como: la muerte del ganado, la pérdida del trabajo o las imposibilidades naturales de la región. Son discursos e imágenes reforzados por estos libros que ensalzan algunos datos soslayando a otros. Según esta misma autor (2012: 77):

\begin{abstract}
«El hecho es que el libro de texto viene cargado de subjetividad y contenidos pocos desarrollados. Una vez que la sobrecarga de un sinnúmero de asuntos pode actuar en detrimento de hechos históricos que para una enseñanza que presenta resultados en la construcción del conocimiento sobre la historia de un lugar, no sólo en la historia de un tiempo distante sino, también, con aquella que se construye y reconstruye cada día»
\end{abstract}

Lajolo y Zilberman (1999) apud (Sena, 2012) sugieren que el libro de texto pueda ser considerado como el primo pobre de la literatura, una vez que sus textos pueden ser superados, ya sea por el paso del tiempo o por el avance en la formación del estudiante. Pero en lo que respecta a los contextos del semiárido brasileño, muchas imágenes han sido cristalizadas de forma temporal. Las imágenes utilizadas en estos materiales no revelan la dinámica socio-cultural y su inserción en la propia dinámica productiva del Brasil y del mundo de este territorio. Por ejemplo, las imágenes de la seca, que además de ser libros publicados en la primera década del año 2000, aún se focaliza la seca de 1952. Donde los descamisados nordestitos se muestran migrando para las grandes ciudades del sur, en los años 30, todavía son unos recursos publicables en los inicios del siglo XXI.

Al evaluarse la dinámica territorial del semiárido, se observa que a cada momento histórico de su formación, un sentido de la naturaleza y del territorio fue 
elaborado y, que a su vez, desencadenó formas de intervención y de surgimiento de actores sociales para realizar las diligencias a escala espaciales conforme el "medio técnico-científico informacional" de cada época (Santos, 1994: 10). De este modo, si en el pasado colonial, existieron las interacciones de la elite local para el centro del poder (metrópolis, sede de la colonia, Capital Federal), en el actual proceso de globalización, las relaciones del semiárido se suceden entre lo local/territorio con lo global. Esas interacciones globalizadas han generado diferentes sentidos tanto de naturaleza semiárica y sus posibilidades de uso en cuanto sentidos de desarrollo territorial en disputa (Carvalho, 202).

Sí esa dinámica territorial es diversa y compleja ella, a su vez, no es acompañada en los materiales didácticos e inclusive ni las imágenes la revela. Los conceptos diseminados por los medias, por los libros de textos y reforzados en la escuela, se mantienen como verdades inmutables. En esta perspectiva, el concepto de semiárido es comprendido como sinónimo de clima, de seca y de miseria. Reis (2010) amplia esta reflexión al afirmar que esta deformación en los educadores que no se reciclen quedara anclada a estos conocimientos cerrados y obsoletos. Lo que se evalúa es que los libros didácticos aún no posibilitan o permitan a los educadores reconocer y afirmar positivamente como sujetos de sus espacios y contextos específicos, pues en estos materiales, el espacio geográfico es expuesto como algo atemporal, neutro y desarticulado. Sena (2012: 80) reflexiona al respecto:

«Los libros de texto necesitan permitir la desmitificación de que en el Sertão falta agua, pues ¿cómo puede llegar tanta agua para los proyectos de irrigación si los autores de los libros afirman que el Sertão es seco? Estas cuestiones precisan ser colocadas en los libros, aunque sea un sólo libro el que paute la perspectiva de la realidad local del alumno, pues infelizmente los libros aún insisten en comparar aspectos del nordeste con otras regiones del Brasil, comparando regiones»

Es cierto que en el Sertão semiárido las condiciones de vida y supervivencia en este vasto territorio configurado por la irregularidad de la lluvia no es nada fácil, pues agua y territorio hacen una relación de territorialidad y, también, de contradicciones. Mientras, se hace necesario desmitificar los discursos encastrados en las imágenes sobre este lugar. Y en esta tarea, muchas organizaciones de la sociedad civil, constituidas en redes sociales, están movilizándose y articulando la idea de la "convivencia con el semiárido brasileño". Sobre estos procesos irá a continuar nuestro debate para luego presentar la propuesta educativa para la contextualización, como forma cultural y subjetiva de reconstruir los saberes en torno del Sertão semiárido.

Los nudos tejidos para construir la propuesta de la convivencia con el semiárido brasileño

La sociedad civil organizada en el semiárido brasileño asumió en los últimos tiempos un papel proactivo, presionando la democratización y el control social de los programas de desarrollo para el territorio. Un contexto de cambio que se inicia en la década de 1980 gracias a la abertura política del país. Surgió en ese periodo el Movimiento Cambia Nordeste, apuntando la situación de exclusión de la región y sus líderes denunciaban las iniquidades socio-históricas. Se lanzaba la idea de que el nordeste es viable (Fávero, 2002). 


\section{II: Educación ambiental y fotografía}

A partir de 1990 se amplía las articulaciones y se crea el fortalecimiento de los sindicatos rurales, asociaciones, cooperativas y ONGs. En este periodo surge una importante red que es la Articulación en el Semiárido Brasileño (ASA). Y en 1990 se implementa, aglutinando varias organizaciones sociales, la propuesta de "convivencia con el semiárido". Esta idea-proyecto mira para otro y nuevo sentido en cuanto al desarrollo territorial, con políticas públicas de inclusión social, de equidad y prudencia con los recursos naturales. Además de la red ASA, surge en el año 2000 una nueva red de Educación para la Convivencia con el Semiárido Brasileño (RESAB) y otras menores. Esas redes pasan a actuar en la desconstrucción de los significados estereotipados y negativos, inspirados en la naturaleza, el campo, la sociedad, la cultura, etc. Es decir, de la gente del Sertão semiárido. El foco de acción es generar nuevas formas de sociabilidad, de tecnologías sociales productivas y educativas posibilitando que, a partir de una nueva base de conocimiento y prácticas con la naturaleza y el territorio semiárido, se establezcan formas de vivir y de producciones adecuadas y adaptadas a las condiciones del semiárido.

\section{La trayectoria de la RESAB en la construcción de la educación contextualizada para la convivencia con el semiárido brasileño}

La RESAB surge a partir de iniciativas productivas y educativas de muchas ONGs, de la Iglesia y de la Secretaría de algunas Universidades Públicas que vienen desarrollando experiencias metodológicas para dar otra significación a la educación ofertada en el semiárido. Los matices curriculares pasaban a ser orientados "para hacer la escuela vincularse a las formas de vida y a las problemáticas existentes de esta región" (RESAB, 2004). Los eventos que antecedieron a la formación de la RESAB fueron el Simposio Escuela y Convivencia con la Seca (1998) y el I Seminario de Educación en el Contexto del Semiárido Brasileño" (2000), ambos realizados en Juazeiro/Bahia. El primero promovió la reunión de las instituciones y de las experiencias, mientras que en el segundo se firmó el Protocolo de Compromiso de las Instituciones presentes, fundándose propiamente la red.

La RESAB, actualmente, congrega a centenas de Instituciones Gubernamentales (Universidades federales y estaduales, Secretarías estaduales y municipales de educación) y diversas ONGs, Agencia de Cooperación Técnica. La red cuenta con el apoyo de los Ministerios de Educación (MEC), Medio Ambiente (MAM) y de Desarrollo Agrario (MDA). Además se han firmado importantes convenios con instituciones de investigación, por ejemplo, con el Instituto Nacional del Semiárido Brasileño (INSA).

La concepción de los procesos educativos de la "Convivencia" expuesto por la RESAB se dimensiona para y a partir de la producción del conocimiento contextualizado. Es decir, "que a partir del contexto se pueda articular los diversos saberes/conocimientos producidos por la humanidad, con el propósito de mejorar las condiciones de vida en el semiárido brasileño" (RE$\mathrm{SAB}, 2004)$. En este sentido, la red actúa con cuatro referencias teórico-práctica: La gestión compartida, el currículo contextualizado, la formación continua y la producción de materiales didácticos y paradidácticos contextualizados, cuyo interés es generar en los niños, jóvenes, hombres y mujeres del semiárido una educación significativa que retrate su realidad.

Con ello, se hace necesario actuar sobre los mate- 


\section{/: Desvelando imágenes de un sertão "seco I y con hambre" y resignificando saberes}

riales didácticos, una vez que éstos son producidos, especialmente, en el centro-sur del país. Materiales compuestos de contenidos peyorativos, limitados, que refuerzan la negatividad y la marginalización del semiárido frente al resto de los otros territorios brasileños. Los programas y libros didácticos que llegan a las escuelas públicas del semiárido no contribuyen al desenvolvimiento de las competencias y habilidades del alumnado, ni tan siquiera los dota de un posicionamiento crítico con respecto a las problemáticas surgidas o creadas para el desarrollo de soluciones prudentes y de respeto a las condiciones del semiárido. Al contrario, no han generado impactos positivos en la mejoría de las condiciones de vida de los grupos humanos que habitan este vasto territorio, cuya población equivale al casi $15 \%$ del total del país.

En las "directrices de la educación para la convivencia con el semiárido brasileño", elaboradas en la I conferencia nacional de la RESAB (I CONESA), realizada del 17 al 20 de mayo de 2006, en Jauzeiro/Bahía, las propuestas promovidas por la Conferencia Estadual (realizadas entre 2004 y 2006) fueron firmadas por los 340 participantes de las Organizaciones Gubernamentales y ONGs, para garantizar el acceso y calidad de la Educación Pública y del respeto a la diversidad y especificidades del semiárido brasileño, consolidando la Educación Contextualizada como un instrumento indispensable en la promoción del desarrollo humano sostenible para este territorio.

La educación en el Brasil y, en especial, en el semiárido tiene una tarea compleja y desafiante, pues ha de pensarse la función y el lugar de la escuela. En el semiárido, las escuelas en su mayoría, funcionan de manera precaria, condiciones que se intensifican en las escuelas de campo/rurales. Además, existe una au- sencia de una política de formación inicial y continua para educadores y educadoras que contemplen la discusión sobre los contextos naturales, históricos y culturales del semiárido. Algo que manifiesta la falta de preparación y conocimiento apropiado de los docentes del semiárido. Otro aspecto desafiador es repensar el currículo, una vez que éste aún se presenta desarticulado de la realidad y amplifica aspectos vulnerables y negativos del semiárido (RESAB, 2006).

Al concebir el campo pedagógico y el aprendizaje fundamentado en la educación contextualizada como camino para otro/nuevo proyecto de sociedad, la idea es que el conocimiento trabajado en la escuela asuma una dimensión de socialización y emancipación del hombre y de la mujer del semiárido y extrapole las dimensiones de la escuela y de los saberes en los trabajos como algo suficiente en sí para la construcción de la cotidianeidad y de un nuevo proyecto social para el semiárido (Martins y Reis, 2004).

La propuesta político-pedagógica de esa red es una construcción colectiva entre la sociedad civil y el Estado. El intercambio de espacios de poder dentro de los programas del Estado, a fin de que la ECSAB sea implementada como política pública. Uno de los itinerarios ha sido la articulación con el Ministerio de Educación y Cultura (MEC) para el conocimiento y adopción del libro de texto "Conociendo el semiárido I y II" en todas las escuelas pública municipales de la enseñaza fundamental I (equivalente a la primaria en España). De este modo, poco a poco la propuesta se está introduciendo en los espacios de debate y está siendo asumida como una de las propuestas centrales de la "convivencia". Junto a la RESAB y la red de Articulación en el semiárido, se están sumando otras redes y actores sociales a esta iniciativa. 


\section{La construcción de un itinerario pedagógico contextualizado para la significación de los saberes}

En los espacios no formales se desenvuelve un trabajo educativo con el uso de los materiales paradidácticos, elaborados por lo general por las propias organizaciones. Estos son: cartillas, folders, vídeos, CDs y DVDs, juegos, etc. El propósito de estos materiales es proporcionar un contenido conceptual y visual diferente al de los materiales didácticos y paradidácticos tradicionales y oficiales. En los espacios formales, como la escuela o la Universidad, la ECSAB va entrando con el proyecto político-pedagógico, a través del currículo contextualizado, como una forma de superar el modelo de currículo establecido por la educación universalista, cuyos conocimientos se inspira en la neutralidad, en la cientificidad y en la fragmentación de los contenidos. La contextualización del conocimiento en los espacios formales se presente en un proceso más puntual. Lo que se observa son algunas escuelas o secretarias (municipales/estaduales), que toman ese itinerario pedagógico como forma de realizar actividades a partir de la vivencia y del cotidiano del alumnado, teniendo como herramientas prácticas motivadoras, por ejemplo, la "huerta pedagógica" o el "estudio de la realidad", entre otros aspectos.

Las actividades citadas visan integrar la cotidianeidad y lo comunitario del alumnado con los contenidos disciplinares, motivándolos a pensar en la comunidad, a conocer mejor la realidad que los rodean y posibilitando conocer su historia, su geografía y su ambiente sociocultural y ambiental. La escuela se torna un lugar de investigación, de hacer-aprender-hacer, pues el alumnado después del estudio de la realidad, desarrolla actividades interdisciplinares, sistematiza el conocimiento adquirido, elabora y reelabora conceptos y des- pués devuelve a la comunidad un ensayo elaborado por ellos mismos, narrando sus impresiones, percepciones y saberes adquiridos.

Otra diferencia significativa es que por medio de la contextualización del saber los estudiantes (niños y jóvenes) pasen a reconocer los ambientes semiáridos en los materiales didácticos y paradidácticos. O sea, ellos se reconocen como parte de este universo presentado en el contenido y en las imágenes de los libros, sintiéndose sujetos históricos, productores de opiniones, de criticidad y de creatividad. Como apunta Martins y Reis (2004: 10):

\begin{abstract}
«La escuela es el espacio privilegiado de intercambio de conocimientos y saberes y de construcción de nuevas referencias. En este sentido, concebimos la escuela como un lugar con color y sabor, donde las opiniones y las ideas más avanzadas y más simples puedan ser comprendidas, siendo que en este espacio, todos son sujetos del conocimiento y del aprendizaje»
\end{abstract}

La contextualización al adentrar en los programas y práctica de la "convivencia" motiva y proporciona a los sujetos el reconocimiento de su mundaneidad (Heidegger, 1981) y territorialidad sertaneja. Se pasa a comprender e intervenir en la complejidad de las manifestaciones de su territorio, y en esa inserción de la trama compleja y diversa del Sertão semiárido, ese sujeto puede encontrar las salidas y alternativas delante de las problemáticas socioeconómicas y vislumbrar perspectivas para la producción de su existencia en el mundo.

\section{Consideraciones finales}

El aprendizaje de las especificidades, fragilidad y potencialidad del semiárido es trabajado en la educación 


\section{/. Desvelando imágenes de un sertão "seco y con hambre" y resignificando saberes}

contextualizada y adentra en los espacios formales y no formales de la educación rompiendo con las narrativas expuestas sobre el Sertão. Este territorio ha sido apenas atendido como unidad fito-climática marcada por la seca, una literatura que desconsidera toda la pluralidad y las múltiples dimensiones materiales e inmateriales que lo atraviesan. Mientras, al dimensionarse el semiárido en sus diversos contextos para la existencia de los sertanejos y sertanejas, otra lectura del territorio emerge y posibilita visualizar la fuerte interacción que se manifiesta en la relación de esa gente con su naturaleza marcada por el semiárido.

La dimensión inmaterial, subjetiva y simbólica-cultural del territorio semiárido adentra en las prácticas, acciones, experiencias y programas desarrollos a partir de la propuesta "convivencia con el semiárido brasileño". Un proceso cultural-educativo contextualizado en los programas y prácticas en el cual los sujetos han significado los sentidos de naturaleza y de territorio, elaborando otros/nuevos signos y emblemas de la identidad territorial sertaneja. Se puede decir, que los elementos físicos, culturales y simbólicos, los regímenes de signos y las subjetividades que componen el territorio semiárido van emergiendo y de aquello que era tratado como un "Sertão seco y de la hambre" se pasa a un territorio de posibilidades de prácticas y de vida.

Con esta nueva lógica, percibir y concebir la naturaleza y el territorio apunta a la necesidad de cualificar los sujetos y a las instituciones que actúen con la lógica de la convivencia. Es un proceso de cambio cultural. En este sentido, se destaca el papel de las acciones desarrolladas con la educación contextualizada. Una propuesta educativa realizada en red, como es el caso de la RESAB. Y cuyas posibilidades para la formación de una nueva generación de profesionales, no

\section{Divulgatio}

solamente en la educación, sino en todas las áreas del saber técnico-científico, se tornen aptas para pensar y desarrollar proyectos de desenvolvimiento pautados a partir de la "convivencia". Estamos ante nuevas posibilidades para que estos profesionales reelaboren y signifiquen las dizibilidades y visibilidades en torno del semiárido y recalifiquen las imágenes representándolas como un Sertão posible.

\section{Notas}

(1) Por estar compuesto por once Estados brasileños (Bahia, Sergipe, Alagoas, Pernambuco, Paraiba, Maranhão, Piaui, Rio Grande do Norte, Ceará, Minas Gerais y Espirito Santo) el semiárido ha sido considerado como "semiárido brasileño" especialmente por las redes de convivencia (ASA, RESAB y otras) que actúan directamente con sus programas socioproductivos, organizativos y educativos en estos Estados.

\section{Referencias}

Albuquerque Jr. (1999). A Invenção do Nordeste e outras Artes. Recife/PE: FNJ, Ed. Massangana, São Paulo: Cortez.

Almeida, M. (2005). "Fronteiras, Territórios e Territorialidades", en Revista da ANPEGE, 2; 103-114.

Almeida, M. (1998). "Em busca do poético do Sertão", en Espaço e Cultura, 6; 35-45.

Bonnemaison, J. (2002). "Viagem em torno do territorio", en: Correa, Z. (Org.). Geografia cultural. EdUERJ : Rio de Janeiro.

Branco, S. (1994). Caatinga: paisagem e o homem sertanejo. São Paulo: Moderna.

BRASIL. Ministério do Meio Ambiente. Secretaria de Recursos Hídricos. PAN-Brasil (2004): Programa de 


\section{II: Educación ambiental y fotografía}

ação Nacional de Combate à Desertificação e Mitigação dos Efeitos da Seca- edição comemorativa 10 anos da CCD - Brasília: MMA/SRH.

Carvalho, L.(2012). Natureza, Território e Convivência. Jundiaí: Paco Editorial.

Cunha, E. (1991). Os sertões. Campanha de Canudos. Rio de Janeiro: Editora Francisco Alves.

Favero, C. (2002). Semiárido: fome, esperança e vida digna. Salvador (BA): EDUNEB.

Heidegger, M. (1981). Todos nós... ninguém: um enfoque fenomenológico do social. São Paulo: Moraes LTDA.

Martins, J. da Silva y Reis, Ed. (2004). Proposta político-pedagógica da RESAB: A convivência com o semi-árido como norteadora do processo educacional no semiárido brasileiro (Rascunho-manifesto em andamento). Secretaria Executiva da RESAB, Juazeiro (BA). Anexo 3.Relatório Final da Consultoria COOPERFAJ/UNICEF.

Mendes, G.. (2009). Sertão se traz na alma? Território/lugar sertão nas filigranas da memória e das representações sociais. Tese (Doutorado em Geografia). Universidade Federal de Sergipe. Núcleo de PósGraduação em Geografia/NPGEO. São Cristóvão, Sergipe.
Reis, Ed. (2010). "Educação para a Convivência com o Semiárido: Desafios e posibilidades", en Semiárido Piauiense: Educação e Contexto. INSA. Campina Grande.

RESAB. Rede de educação do semiárido brasileiro (2006). Diretrizes da Educação para a Convivência com o Semiárido Brasileiro. Juazeiro - BA: Selo Editorial RESAB.

RESAB (2004). REDE DE EDUCAÇÃO DO SEMIARIDO BRASILEIRO. Secretaria Executiva da RESAB. Projeto inclusão, universalização e qualidade da educação no semiárido brasileiro. Juazeiro (BA).

Santos, J. Marques dos (2005). "Ecologia de homens e mulheres do semi-árido", en: Santos, J. Marques do (Org). Ecologia de homens e mulheres do semi-árido. Paulo Afonso (BA): Editora Fonte Viva.

Santos, M. (1994). Técnica, espaço, tempo: globalização e meio técnico - cientifico Informacional. São Paulo: Editora Hucitec.

Sena, R. (2012). O Semiárido na pauta dos livros didáticos: antigas abordagens e novas pespectivas. Juazeiro: UNEB/DCH III. 